\title{
Effect of polycaprolactone nanofibers on the vibratory behaviour and the damage resistance of composite laminates
}

\author{
Cristobal Garcia ${ }^{1, *}$, Irina Trendafilova ${ }^{1}$, and Andrea Zucchelli ${ }^{2}$ \\ ${ }^{1}$ University of Strathclyde, Department of Mechanical and Aerospace Engineering, 75 Montrose \\ Street, G1 1XJ, Glasgow, UK \\ ${ }^{2}$ University of Bologna, Department of Industrial Engineering, Viale Risorgimento 2, 40125, \\ Bologna, Italy
}

\begin{abstract}
Aircrafts, bridges, wind turbines and other civil structures made of composite materials are frequently subjected to vibrations, which are responsible for a considerable number of accidents. One of the methods to reduce the vibrations is the incorporation of nanofibers in the composite structures. The main purpose of this study is to investigate the effect of the inclusion of polycaprolactone nanofibers on the vibratory behaviour of composite laminates. For this purpose, the vibratory behaviour of nano composites (with nanofibers) and standard composites (without nanofibers) is investigated with the purpose of acquiring their natural frequencies and the damping ratio. The results indicated that the inclusion of polycaprolactone nanofibers in composites increased the damping ratio, however it did not change significantly the natural frequencies. Furthermore, the paper investigates the effect of polycaprolactone nanofibers on the damage resistance of glass fibre composites. For this purpose, a finite element model is used to simulate the damage caused by mechanical impact in standard and nano composites. The numerical simulations show that the interleaving with nanofibers increased the damage resistance considerably. This study contributes to the knowledge about the vibration behaviour and the damage resistance of composites interleaved with polycaprolactone nanofibers. It is demonstrated that the interleaving with polycaprolactone fibres can play an important role for reducing the vibrations and increasing their impact damage resistance in composite structures as aircrafts.
\end{abstract}

\section{Introduction}

The incorporation of nanofibers in composite mats can drastically improve some material properties. For example, [1] reports that the inclusion of nylon nanofibers in composite laminates increases the damping, which plays an important role for supressing vibrations. Other authors as [2] reported that composites interleaved with nanofibers are less prone to delamination as compared to standard composites. [3] also demonstrates that nano-modified

* Corresponding author: cristobal.garcia@strath.ac.uk 
composites are more resistant to impact damage. Thus, the nanofibers can be used to enhance the properties of the composite mats used in aircrafts, bridges and other structures.

Recently, the dynamic behaviour of composite laminates has been widely investigated regarding its application in delamination detection [4] and structural health monitoring [5]. However, there are still very few publications to explore the vibratory behaviour of nanomodified composites. [6] studied the first natural frequency and the damping ratio of carbon laminates reinforced with nylon nanofibers. Other works as [7] analysed the natural frequencies of composites interleaved with carbon nanotubes. It has to be said that the investigation of the effect of nanofibers on the dynamic/vibratory behaviour of composite laminates is of utmost importance for numerous applications.

The aim of this work is to investigate the influence of polycaprolactone nanofibers on the vibratory behaviour of glass fibre composite laminates. For that purpose, composites reinforced with polycaprolactone nanofibers and standard composites (without nanofiber interleavings) are subjected to experimental investigation to assess their vibratory behaviour. The free decay vibration response of the composite specimens is used to assess the influence of the polycaprolactone nanofibers on the natural frequencies and the damping ratios of the investigated composite laminates. To the best of our knowledge, this is the first attempt to study the vibrational behaviour of composites interleaved with polycaprolactone nanofibers.

This study includes some important findings which make an important contribution regarding the application of composites with polycaprolactone nanofibers. Initially, the paper demonstrates experimentally that the incorporation of nanofibers reduces the amplitude of the vibrations, which have important applications for composite structures in which vibrations are a source of problems. Subsequently, this work shows theoretically that composites reinforced with nanofibers are more resistant to damage and delamination than standard composites, which is important for the health of the composite mats used in aircrafts, spacecrafts and other structures made of composite mats. It is important to mention that the results obtained in the finite element simulations are in good agreement with experimental results published previously in [8].

The rest of the paper is organized as follows: Section 2 explain the fabrication process of composites modified with and without polycaprolactone nanofibers. Section 3 shows the vibration test used to assess the natural frequencies and the damping of the composite specimens. The finite element model used to simulate the impact damage resistance of the nano-modified composites is presented in \& 4. Section 5 presents and discusses the experimental and numerical results. The paper ends with some conclusions and potential applications of the polycaprolactone modified composites.

\section{Fabrication of composites with and without nanofibers}

Fig. 1 shows the structural design of the standard and nano composite mats used in this study. Composite mats without nanofibers (known as standard composites) were fabricated by hand lay-up of eight layers of glass fibre/epoxy prepreg as shown in fig. 1(a). The dimensions of the composite beams are $(168 \times 32 \times 3) \mathrm{mm}$ with a stacking sequence of $[0,90,0,90]_{\mathrm{s}}$. After the lay-up, the specimens were cured in an autoclave under $150{ }^{\circ} \mathrm{C}$ and for about one hour.

Composite laminates reinforced with nanofibers (known as nano composites) were also manufactured by hand lay-up with identical sizes and stacking sequence as the standard composites. However, six membranes of polycaprolactone nanofibers prepared using the 
electrospinning technique as indicated in [9] were interleaved into the composite interfaces as depicted in fig. 1(b). After the lay-up, the nano composites were cured in an autoclave according to supplier's specifications. It is worthy to mention that the incorporation of nanofibers into the composite interfaces did not increase the thickness significantly as compared to the standard composites.

(a)

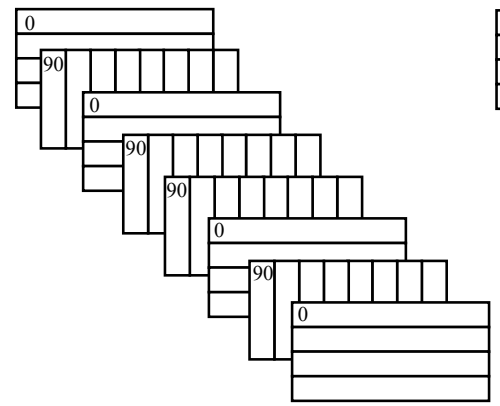

(b)

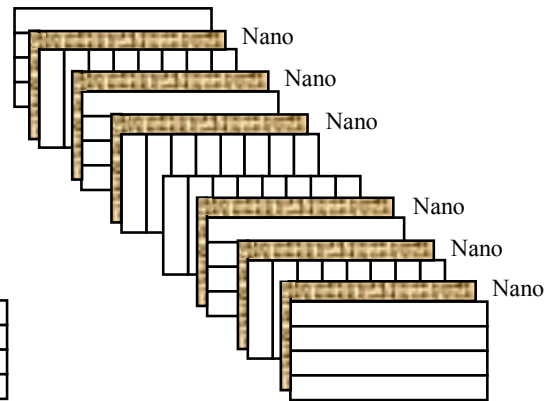

Fig. 1. Structural design of the standard composites (a) and the nano composites (b).

\section{Experimental investigation}

This section introduces the experimental investigation used to assess the dynamic behaviour of the fabricated composite specimens. The purpose of the test is to experimentally estimate the natural frequencies and the damping of the glass fibre reinforced polymer (GFRP) composites with and without polycaprolactone nanofibers.

Fig. 2 shows a schematic description of the experimental set-up. Initially, the composite beams were clamped at both ends and subjected to free vibration by applying an instantaneous force at the middle of the beam using a modal hammer. Then, the free vibration response of the beams was acquired by using an accelerometer. The dynamic signals were recorded for $0.5 \mathrm{~s}$ at a sampling frequency of $5 \mathrm{kHz}$. Eventually, the vibration response was used to calculate the first five natural frequencies using the Fast Fourier Transform and the damping ratio by means of the Logarithm Decrement Method. It is important to mention that each vibration measurement was repeated ten times per specimen and the results given are in terms of average for all the measurements.

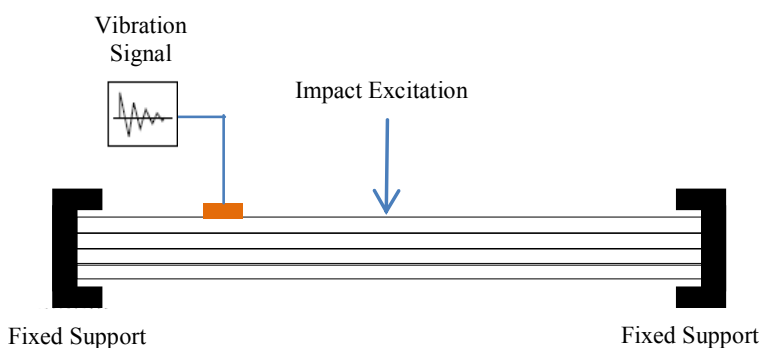

Fig. 2. Experimental set-up to measure the vibrations in standard and nano composites. 


\section{Theoretical investigation through FE modelling the impact damage resistance of standard and nano composites}

The aim of this section is to present the finite element model used to simulate the impact damage resistance of the fabricated composite specimens with and without polycaprolactone nanofibers. The numerical simulations are performed using ANSYS commercial software. The composite layers made of glass fibre and epoxy resin are simulated using the element type Solid 185 and the material constants provided by ANSYS engineering data [10]. The interfaces with polycaprolactone nanofibers (known as nano) and epoxy resin (known as standard) are modelled using cohesive elements and the cohesive parameters which are indicated in Table 1.

Table 1. Cohesive zone parameters used to simulate the interfaces in standard and nano composites.

\begin{tabular}{c|cccc}
\hline Parameter & Abreviation & Standard & Nano & Units \\
\hline Maximum normal traction & $\mathrm{T}_{\mathrm{n}}{ }^{\max }$ & 5 & 2.8 & $\mathrm{MPa}$ \\
Normal displacement at debonding & $\delta_{\mathrm{n}}{ }^{\mathrm{c}}$ & 0.27 & 0.35 & $\mathrm{~mm}$ \\
Maximum tangential traction & $\mathrm{T}_{\mathrm{t}}{ }^{\max }$ & 5 & 2.8 & $\mathrm{MPa}$ \\
Tangential displacement at debonding & $\delta_{\mathrm{t}}{ }^{\mathrm{c}}$ & 0.27 & 0.35 & $\mathrm{~mm}$ \\
Ratio & $\alpha$ & 0.02 & 0.015 & dimensionless \\
Non-dimensional weighting parameter & $\beta$ & 1 & 1 & dimensionless \\
\hline
\end{tabular}

\section{Results and discussion}

\subsection{Effect of polycaprolactone nanofibers on natural frequencies}

The effect of polycaprolactone nanofibers on the vibratory behaviour of composite mats is analysed in this paragraph. For the purpose, the natural frequencies of the standard and nano composites are measured using the vibration test explained in section 3 .

Table 2 shows the first five natural frequencies measured in the composite laminates with and without nanofibers. The effect of polycaprolactone nanofibers is analysed in the table through the variation of the natural frequencies between the standard and nano composites. The results show that the natural frequencies of the composites with nanofibers are smaller as compared to the standard ones. It can be clearly seen that the variation of the natural frequencies due to the nanofibers is very small (less than $4.7 \%$ ). The minimum changes in the natural frequencies are attributed due to the small variations in mass and stiffness caused due to the interleaving with nanofibers.

Table 2. Effect of polycaprolactone nanofibers on the natural frequencies.

\begin{tabular}{c|ccc}
\hline $\begin{array}{c}\text { Natural } \\
\text { frequencies }\end{array}$ & $\begin{array}{c}\text { Standard } \\
(\mathrm{Hz})\end{array}$ & $\begin{array}{c}\text { Nano } \\
(\mathrm{Hz})\end{array}$ & $\begin{array}{c}\text { Variation } \\
(\%)\end{array}$ \\
\hline First & 484.5 & 461.5 & 4.7 \\
Second & 930.9 & 923.2 & 0.8 \\
Third & 1373.8 & 1369.8 & 0.3 \\
Fourth & 1857.5 & 1843.2 & 0.8 \\
Fifth & 2303.8 & 2278.0 & 1.2 \\
\hline
\end{tabular}

Some previous studies published similar results. For example, [7] reported that the natural frequencies of epoxy resin increased up to $7 \%$ due to the inclusion of carbon nanotubes. Other authors as [1] observed the natural frequencies of glass fibre epoxy 
laminates increase up to $4 \%$ due to the interleaving with nylon nanofibers. From the results obtained, it can be concluded that the changes in the natural frequencies are minuscule and inconclusive as these variations are in the region of experimental and measurement error.

\subsection{Effect of polycaprolactone nanofibers on damping ratio}

The aim of this section is to investigate the effect of polycaprolactone nanofibers on the damping of glass fibre composite laminates. The damping of the standard and nano modified laminates was calculated using experimental procedure explained in section 4 .

The experimental results are given in table 3 and show the damping ratio for the standard and nano composites. Furthermore, the table includes the variation of the damping ascribed to the nanofibers. The results show that the damping increased with an $8.3 \%$ due to the incorporation of polycaprolactone nanofibers. This increase can be explained due to the good interaction between polycaprolactone nanofibers and epoxy resin which will result in a more dissipation of energy and a higher damping ratio. Similar results are reported in other works. In [1] the damping of glass fibre epoxy laminates increases a $36 \%$ due to the inclusion of nylon nanofibers. Other publications as [11] found that the damping ratio of composite specimens increases up to $28 \%$ due to the interleaving with jute nanofibers. In conclusion, it can be said that the inclusion of polycaprolactone nanofibers in laminates can be used to reduce the amplitude of the vibrations due to a higher damping ratio as compared to standard composites. As a result, composites interleaved with nanofibers can be utilized to build composite structures (e.g. aircrafts or bridges) with smaller amplitude vibrations.

Table 3. Effect of polycaprolactone nanofibers on the damping ratio.

\begin{tabular}{c|ccc}
\hline & $\begin{array}{c}\text { Standard } \\
\text { (dimensionless) }\end{array}$ & $\begin{array}{c}\text { Nano } \\
\text { (dimensionless) }\end{array}$ & $\begin{array}{c}\text { Variation } \\
(\%)\end{array}$ \\
\hline $\begin{array}{c}\text { Damping } \\
\text { ratio }\end{array}$ & 0.012 & 0.013 & 8.3 \\
\hline
\end{tabular}

\subsection{Effect of polycaprolactone nanofibers on impact damage resistance}

This paragraph analyses the effect of polycaprolactone nanofibers on the impact damage resistance of glass fibre composites. For this study, the finite element model introduced in section 4 is used to simulate the damage caused by an energy impact of $24 \mathrm{~J}$ in standard and nano composites.

Fig. 3 shows that the results obtained in the finite element model simulations. The legend scale on the left refers to the damage status of the composite beam, where the strong blue colour $(0 \%)$ represents that the composite is undamaged and the red colour $(100 \%)$ indicates that the composite is severe damaged. The green colour in between are associated to partial damage states. The figure clearly shows that the area damaged for the standard and nano composite are $175 \mathrm{~mm}^{2}$ and $126 \mathrm{~mm}^{2}$ respectively. Therefore, the composite reinforced with polycaprolactone nanofibers (known as nano) is less damage than the standard one with a damage extension a $28 \%$ smaller than the standard composite. This is attributed due to the links between the polycaprolactone nanofibers and the composite laminates which results in a more dissipation of energy as compared the standard composites. 
Damage status
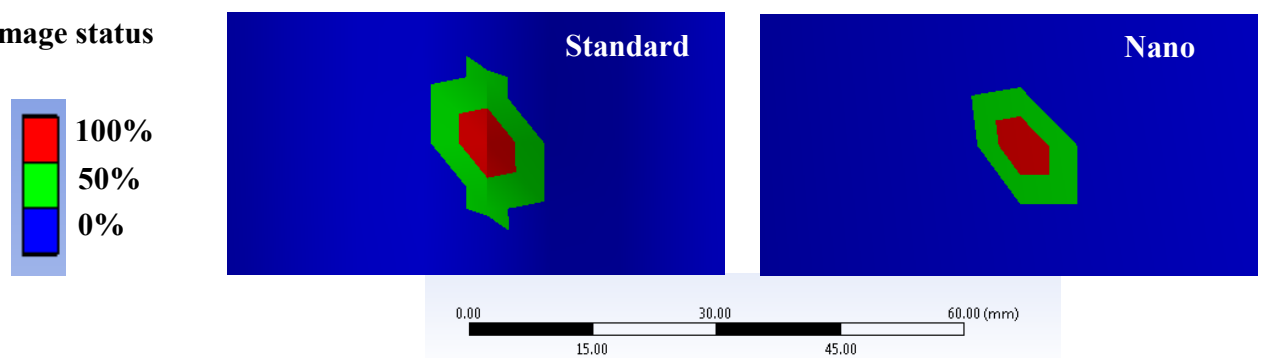

Fig. 3. Area damaged after same impact in standard composite (a) and composite with nanofibers (b).

The results obtained in the simulations are verified with the experimental results published in [8], where the area damaged after the same energy impact decreased from 170 $\mathrm{mm}^{2}$ to $125 \mathrm{~mm}^{2}$ due to the interleaving with polycaprolactone nanofibers. Other works as [3] also report that the inclusion of nanofibers enhance the impact damage resistance. As conclusion, it can be said that polycaprolactone nanofibers can be used to increase significantly the impact damage resistance in composite laminates, which is important for the composite structures used in airplanes, wind turbines and so on where the damage caused by impacts as per example bird strikes is a main concern.

\section{Conclusion}

The aim of this work is to investigate the effect of polycaprolactone nanofibers on the vibratory behaviour and impact resistance of composite laminates. The negligible changes in the natural frequencies demonstrated that the standard and nano composites retain the same working frequency range. The main achievement of the paper is to show that the inclusion of polycaprolactone nanofibers in laminates can be used to increase the damping and the impact damage resistance of composite laminates. This can be used to build aircrafts or other structures made of composite mats with smaller amplitude vibrations and higher resistant to impacts as bird strikes or hailstorms.

\section{References}

[1] C. Garcia, J. Wilson, I. Trendafilova, L. Yang, Compos. Struct., 176, 923-932 (2017)

[2] C. Garcia, I. Trendafilova, A. Zucchelli, J. Contreras, MATEC Web Conf., 148, 14001 (2018)

[3] P. Akangah, S. Lingaiah, K. Shivakumar, Compos. Struct., 92, 1432-1439 (2010)

[4] R. Sultan, S. Guirguis, M. Younes, E. El-Soaly, IJMERR, 1, 227-236 (2012)

[5] F. Inam, B.R. Bhat, T. Vo, W.M. Daoush, Ceram. Int., 40, 3793-3798 (2014)

[6] R. Palazzetti, A. Zucchelli, I. Trendafilova, Compos. Struct., 106, 661-676 (2013)

[7] S.C. Her, C.Y. Lai, MDPI, 6, 2274-2284 (2013)

[8] H. Saghafi, T. Brugo, G. Minak, A. Zucchelli, Eng. Solid Mech., 3, 21-26 (2015)

[9] L. Van der Schueren, B. De Schoenmaker, O.I. Kalaoglu, K. De Clerck, Eur. Polym. J., 47, 1256-1263 (2011)

[10] The materials constants used to simulate the composite layers are $\mathrm{E}_{\mathrm{x}}=45 \mathrm{GPa}, \mathrm{E}_{\mathrm{y}}=\mathrm{E}_{\mathrm{z}}=$ $10 \mathrm{GPa}, v_{\mathrm{xy}}=\mathrm{v}_{\mathrm{xz}}=0.3, \mathrm{v}_{\mathrm{yz}}=0.4, \mathrm{G}_{\mathrm{xy}}=\mathrm{G}_{\mathrm{xz}}=5 \mathrm{GPa}, \mathrm{G}_{\mathrm{yz}}=3.8 \mathrm{GPa}$ and $\varphi=2000 \mathrm{Kg} \mathrm{m}^{-3}$.

[11] K.T.B. Padal, K. Ramji, V.V.S. Prasad, IJETAE, 4, 753-759 (2014) 